\title{
Computational Model for the Evaluation of Reinforced Concrete Silos Subjected to Thermal Load
}

\author{
Walid M. A. Khalifa \\ Civil Engineering Department, \\ Hail University, Saudi Arabia \\ and Fayoum University, Egypt \\ khalifawalid@yahoo.com
}

\author{
Khaled F. O. El-Kashif \\ Structural Engineering Department, \\ Cairo University, \\ Giza, Egypt \\ kashifcairo@yahoo.com
}

\begin{abstract}
Silos are special structures subjected to many different unconventional loading conditions like temperature differences which result in unusual failure modes. So, it is necessary for many codes to maintain and study the effect of thermal loads in design. The evaluation of design and construction practices is an essential step in the development of the design code for reinforced concrete (RC) silos, especially in arid zones like Saudi Arabia. This work evaluates the effect of thermal loads on silo wall design in terms of applied forces and stresses. These thermal loads affect the silo walls in two main manners, tangential oriented stresses (circumferential stress) due to thermally induced surcharge pressure during cooling of a filled silo structure and stresses due to differences of temperature across the wall thickness. A computation analytical finite element model (FEM) has been applied in a commercial analyzing program (SAP 2000 version 16). Various code provisions were used with comparison with the FEM results. For hoop forces, EU regulation, German standard, and Polish norm provisions were compared with a linear FEM with two parameters, wall thickness and temperature difference. For oriented stresses in silo wall, the American concrete institute (ACI) provisions were used in comparison with linear and nonlinear FEM with the same two parameters, wall thickness and temperature difference. This work showed that the nonlinear analysis of FEM has good matching with the corresponding values in ACI, leading to the conclusion that nonlinear analysis is more accurate than linear analysis. Moreover, the study results of hoop forces showed a distinct pattern with the temperature difference, silo radii, and insignificant silo wall thickness for each of FEM, EU, and Poland codes. This study is used for the rapid determination of critical areas of concern for critical loading combinations and for varying silo configurations.
\end{abstract}

Keywords-code provisions; finite element model (FEM); silos; thermal load

\section{INTRODUCTION}

Silos are commonly used for storing bulk solid materials, cement, granular materials, and fluids. Silos are considered special structures subjected to unconventional loads under various loading conditions, which cause failure if one or more of these loads are not taken into consideration, resulting in partial or total collapse [1]. A thermal load on silos is one of the main input loads in the design process. So it is necessary for many codes to maintain and study the effects of thermal loads in analysis, design, construction, and maintenance. Codes put many restraints in the design and analysis phases in the form of extra input loads or pressure and/or additives output straining actions.

The ACI standard practice devotes sections to design, material, and construction recommendation and requirements for precast, convention cast-in-place, and post-tensioned concrete silos, stave silos, and stalking tubes for storing granular material. ACI recommends calculating an additional moment because of the thermal effect under several conditions [2]. The thermal moment can be calculated as in [3]. Variation in the air temperature around the silo walls with ensiled granular material is a very important load, it increases the wall stress because wall radially does not undergo free contraction. Laboratory studies proved that lateral pressure varies with ambient temperature and static pressure [4]. There are two ways to calculate the additional moment and thus steel reinforcement rebar. The first one is the resulting moment [3]. The second is according to shrinkage and temperature steel requirements of ACI 318 applying silo design consideration [5]. An additional area of reinforcement shall satisfy the minimum ratio of deformed temperature reinforcement area to gross concrete area [6]. The thermal effect caused by the stored hot or cold material can be calculated in a form of extra moment. But, in designing structural members for temperature differences, usually a certain amount of temperature variation can be neglected, thus, authors in [7] agree to neglect the first $26.67^{\circ} \mathrm{C}$ of temperature difference $(\Delta T)$. The temperature of the ensiled granular material drops significantly at the inner face of the silo wall. Because of that, the granular material, e.g. cement, acts as an insulating material in which the temperature drops linearly and its thickness can be estimated as 8 inches [8]. From these conditions and from the principles of heat transfer, the thermal resistance of the silo wall can be estimated according to [9] based on the assumptions shown in [10].

The European committee for standardization created and published many parts and sections of general regulations and recommendation in design and construction [11]. There are two ways to calculate the unloading effective elastic modulus of the 
stored granular material. The first is the direct assessment from laboratory testing. The second is indirect assessment depending on the vertical pressure at the base of silo wall as in [11]. The German standard provides general regulations and actions for the design and construction stages for the storage silos [12]. The German norm concerns actions and loads on silo bins. It provides an additional horizontal pressure calculated exactly as in the Euro code. The Polish norm provides static calculations, design, construction and operation for reinforced concrete silos [13]. Polish norm recommended an additional latitudinal tensile force due to decline in temperature. Today, FEM is the conjunction of three main sections: high technology computer programs, matrix structural analysis, and theory of variation approximation [14]. FEM is also called nodal method because of the interconnected points (nodes) that connect the finite elements. It is also called discretization method because it divides the body or the object into smaller parts or elements connected together at points, nodes, lines, surfaces, and volumes [15]. The material induced lateral pressure of RC silo in static condition using the FEM in ABAQUS software has been analyzed in [16].

The main object of this work is to evaluate the effect of thermal loads on silo wall design in terms of applied forces and stresses. Thermal loads affect silo walls mainly in two manners: tangential oriented stresses (circumferential stress) due to thermally induced surcharge pressure during cooling, and stresses due to temperature differences at silo walls. A computation analytical FEM has been applied using SAP 2000 v. 16. Various code provisions were used comparably with the FEM results. For oriented stresses in silo wall, ACI provisions were used in comparison with a linear and nonlinear FEM in a parametric study of wall thickness and temperature difference. For hoop forces, the EU regulation and Polish norm provisions were used in comparison with a linear two parameter FEM (wall thickness and temperature difference). These will be used for rapid determination of critical areas for critical loading combinations and for varying silo configurations.

\section{LINEAR AND NONLINEAR FEM ANALYSIS}

FEM is a numerical technique used to solve complex problems in structural mechanics by dividing the geometry into smaller parts (finite elements) by having approximate solutions for partial differential equations [15]. This study uses FEM in SAP 2000 v. 16. The RC silos are considered as load bearing members divided into elements. The stiffness of these structures is independent on the values of the applied loads. The applied loads are proportional to deformation, and when the loads are removed, the body comes back to its former shape [17]. This behavior is known as linear based on some assumptions included in [18]. That leads to the term called elasticity which is the proportion of the strain resulting from applying a known stress [19]. Most of codes provide empirical equations to calculate the modulus of elasticity of concrete using the compression strength as:

$$
E_{c}=k\left(f_{c u}\right)^{1 / 2}
$$

where $E_{c}$ is the concrete modulus of elasticity $\left(\mathrm{N} / \mathrm{mm}^{2}\right), f_{c u}$ is the compressive strength of a concrete cube at 28 days
$\left(\mathrm{N} / \mathrm{mm}^{2}\right)$, and $k$ is an empirical constant, which equals to 4400 [20], 4733 [6], or 5000 [21].

To fully understand linear and nonlinear analysis, they can be applied to a well-known stress-strain relationship [9]. The stress-strain behavior is divided into: pre-peak in which the structure has linear elastic response for a very minor strain, and post-peak where excessive deformation (strain) occurs with low stress level. This stage is called plastic response. It is obvious that most of structure behaviors are nonlinear, but using linear analysis for such cases doesn't create a great divergence (it can be neglected) from the results of nonlinear analysis. Using linear analysis, in cases where nonlinear analysis is more accurate, may be preferred if the accuracy is low or an overview of the structure behavior or displacement orientation is required. Linear analysis may not be accurate or perfect, however, it is money and time saving. On the other hand, nonlinear analysis is accurate and takes all the applied stresses and resulting strains into consideration. The changes resulting from deformations may cause changes in the structure shape and stiffness, furthermore loads may change their orientation and supports would be changed with regards to large deformations during loading [22]. Nonlinear analysis is taking all of these factors into account.

\section{CODES AND PRECAUTIONS}

ACI, EU and Polish codes in concrete silos subjected to thermal loads were studied. Each of these codes puts some precautions in the form of equations as additional input loads or output straining actions.

\section{A. $A C I$}

The additional moment $\left(\mathrm{M}_{\mathrm{t}}\right)$ assigned by ACI [3] is:

$$
M_{t}=\left(E_{w} t^{2} \alpha_{w} \Delta T\right) /[12(1-\vartheta)]
$$

where $M_{t}$ is the thermal bending moment per unit of wall height or width, $E_{w}$ is the modulus of elasticity of the silo wall, $\mathrm{t}$ is the silo wall thickness, $\alpha_{w}$ is the thermal coefficient of expansion of silo wall, $\Delta T$ is the temperature difference between the inside and outside face of the silo wall, and $\vartheta$ is the Poisson's ratio for concrete, assumed to be 0.2 . The additional moment required to resist the additional stresses due to thermal load, is a function of temperature difference $\Delta T$ and silo wall thickness $t$. Thus, $\Delta T$ and $t$ will be the parametric elements in the ACI equation, so case studies will be performed on them separately. Wheat is the stored granular material used as input data. The temperature difference should be classified into two divisions:

\section{1) Uniform and Nonuniform}

Uniform temperature difference means that the temperature is equal through the inner and the outer of the silo wall, despite the differences from the daily variation. Nonuniform temperature difference means that there is a difference between the inner and the outer face of the silo wall at any instant. It is worth mentioning that the moment resulting from the case of nonuniform temperature difference is larger and more critical than the one in the uniform case. One case of nonuniform temperature difference distribution is presented in [23]. 


\section{2) Positive and Negative}

Positive temperature difference means that the temperature inside the silo wall is lower than the temperature outside (ambient temperature). Consequently silo walls tend to expand outward generating thermal loads stresses. The opposite stands for negative temperature difference. The silo walls tend to contract resulting in more stresses due to thermal load and granular material reaction pressure. Obviously, negative temperature difference is more critical than the positive one because it generates more lateral pressure on silo walls in the case of full granular material load.

The assumptions of temperature difference neglect the tensile strength of concrete and the effects of wind direction on temperature difference, temperature variation between different elevations, and the direction of sun rays. In other words, it is assumed that temperature varies only radially. When applying negative thermal loads to the silo walls, extra stresses are generated not only by the temperature difference, but also by the extra horizontal pressure from the stored material similar to passive earth pressure. The extra horizontal pressure depends mainly on the properties of the granular material (stiffness, density, friction coefficient, etc.). In the analysis of silo under negative temperature difference using FEM, the contact between the silo walls and the stored material is modeled by elements having radial oriented elastic area constrains under compression only $(-\Delta T)$ [8]. The granular material stiffness $C_{g}$ can be calculated according to the deformation equilibrium of an elastic ring in contact with the ensiled granular material with the validation of applied spatial stress relationship:

$$
C_{g}=E_{g} /\left(R\left(1-\vartheta_{g}\right)\right)
$$

where $E_{g}$ is the modulus of elasticity of the stored granular material, and $\vartheta_{g}$ is the Poisson's ratio of the stored granular material. Since the granular materials have properties similar to soil, for the evaluation of the grain elasticity modulus, the values of $E_{g}$ and $\vartheta_{g}$ can be estimated as in [8]. EU and polish codes will be shown in Section V.

\section{B. European Union Regulation}

The Eurocode assigns an additional horizontal pressure $P_{h}$ [11], required to resist extra stresses due to thermal loads. The horizontal pressure, shown in (4), is a function of $\Delta T$, $\mathrm{t}$, and silo radius $r$. Thus, $\Delta T, t$ and $r$ will be the parametric study elements in the Eurocode equation:

$$
P_{h}=\left(C_{T} \alpha_{w} \Delta T E_{w}\right) /\left((r / t)+(1-\vartheta)\left(E_{w} / E_{s u}\right)\right)
$$

where $C_{T}$ is the temperature load multiplier. It equals to 1.2 when laboratory testing is used to obtain the unloading effective elastic modulus. It also equals to 3 when the unloading effective elastic modulus is simplified from the density, $\alpha_{w}$ is the coefficient of thermal expansion of the silo wall, $E_{w}$ is the modulus of elasticity of the silo wall, $\vartheta$ is Poisson's ratio of the stored material, which can be assumed to be equal to 0.3 , and $E_{s u}$ is the unloading effective elastic modulus of the stored material. There are two ways to calculate the unloading effective elastic modulus of the stored granular material. The first is the direct assessment from laboratory testing as in EN 1991-4:2006 annex C section C10.1. The second is indirect assessment. An estimated value for $E_{s u}$ can be calculated from:

$$
E_{s u}=\chi P_{v f t}
$$

where $P_{v f t}$ is the vertical pressure at the base of the silo wall, $\chi$ is the modulus contiguity coefficient:

$$
\chi=7 \gamma^{3 / 2}
$$

$\gamma$ is the density of the stored material in $\mathrm{kN} / \mathrm{m}^{3} \cdot \chi$ may be estimated as 70 for dry grains, 100 for small mineral particles, and 150 for large hard mineral particles. $P_{v f t}$ is calculated from:

$$
\begin{aligned}
& P_{v f t}=\left(P_{h o} Y_{J}\right) / K \\
& P_{h o}=\gamma K z_{o} \\
& z_{o}=1 /[(K \mu)(A / U)]
\end{aligned}
$$

where $P_{h o}$ is the horizontal pressure at the big depth due to stored material, $Y_{J}$ is the Janssen pressure depth variation function, $K$ is the lateral pressure ratio, $z_{o}$ is the Janssen characteristic depth, $z$ is the depth below the surface of the stored material, $\mu$ is the coefficient of wall friction for the material sliding on the vertical wall, $A$ is the cross section area of the silo plan, and $U$ is the internal perimeter of the cross section of the silo plan. For circular plan silos $A / U=r / 2$.

$$
\begin{aligned}
& Y_{J}=1-\exp \left(z / z_{o}\right) \\
& z=h-2 / 3\left(r \cdot \tan \phi_{r}\right)
\end{aligned}
$$

where $h$ is the height of the silo wall, and $\phi_{r}$ is the angle of repose of the stored material. $\mathrm{P}_{\mathrm{vft}}$ can be also calculated as:

$$
\begin{aligned}
P_{v f t} & =\gamma z_{v} \\
z_{v} & =h_{o}-1 /(n+1) \\
& \times\left[z_{o}-h_{o}-\left\{\left(z+z_{o}-2 h_{o}\right)^{n+1} /\left(z_{o}-h_{o}\right)^{n}\right\}\right] \\
n= & -\left(1+\tan \phi_{r}\right)\left(1-h_{o} / z_{o}\right)
\end{aligned}
$$

where, $z_{v}$ is the depth used for vertical stress calculations, $h_{o}$ is the depth below the equivalent surface to the base of the top pile, and $n$ is the power in hopper pressure relationship. Then, the hoop force $F_{E}$ is using the structural mechanics equilibrium principles as $[11,24]$ :

$$
F_{E}=r P_{h}
$$

\section{Polish Norm}

The Polish norm provides static calculations, design, construction and operation for reinforced concrete silos. PN-B03262: 2002 is the Polish standard [13] concerning loads and actions on R.C. silos. It recommended an additional latitudinal tensile force $F_{P}$ due to temperature decline:

$$
F_{P}=\left(r E_{g} \alpha_{w} \Delta T_{m}\right) /\left(\left(r E_{g}\right) /\left(t E_{w}\right)+1-\vartheta_{g}\right)
$$


where $r$ is the internal radius of the cylindrical silo wall, $t$ is the thickness of the silo wall, $E_{g}$ is the modulus of elasticity of the stored granular material, $E_{w}$ is the modulus of elasticity of the silo wall, $\alpha_{w}$ is the coefficient of thermal expansion of the silo wall, $\vartheta_{g}$ is the Poisson's ratio of stored granular material, $\Delta T_{m}$ is the average daily temperature at the silo wall. The hoop force using Eurocode as in (15) is compared with the Polish Norm required a compensating force as shown in (16), and the output hoop force from the FEM computer program analysis.

\section{MOMENT ANALYSIS UNDER THERMAL LOAD}

\section{A. Temperature Difference}

Estimation of the maximum vertical moment of the RC silo subjected to temperature difference can be summarized in silo dimensions, concrete characteristics and granular material properties as shown in Table I. The calculated moment according to (2) and the data shown in Table II, can be written as a function of $\Delta T$ as: $M_{t}=0.13088946 \Delta T$ ton.m $/ \mathrm{m}$. Using the FEM program to show the effects of thermal stresses on silo walls, the outputs of the FEM analysis in silo walls are defined as: F11 is the hoop force, M11 is the hoop moment, F22 is the vertical force, and M22 is the vertical moment.

TABLE I. SILO DIMENSIONS, CONCRETE CHARACTERISTICS AND GRANULAR PROPERTIES

\begin{tabular}{|c|c|c|c|}
\hline \multicolumn{2}{|c|}{$\begin{array}{c}\text { Silo dimensions and concrete } \\
\text { characteristics }\end{array}$} & \multicolumn{2}{c|}{ Granular material (wheat) properties } \\
\hline $\begin{array}{c}\text { Total height of } \\
\text { the silo wall }\end{array}$ & $H=30 \mathrm{~m}$ & $\begin{array}{c}\text { Angle of internal } \\
\text { friction }\end{array}$ & $\phi_{i}=30^{\circ}$ \\
\hline $\begin{array}{c}\text { The inner } \\
\text { radius }\end{array}$ & $R=5 \mathrm{~m}$ & Density & $\gamma=0.9$ ton $/ \mathrm{m}^{3}$ \\
\hline $\begin{array}{c}\text { Concrete } \\
\text { compressive } \\
\text { strength }\end{array}$ & $f_{c u}=3000 \mathrm{ton} / \mathrm{m}^{2}$ & $\begin{array}{c}\text { Coefficient of } \\
\text { friction }\end{array}$ & $f=0.38$ \\
\hline $\begin{array}{c}\text { Modulus of } \\
\text { elasticity }\end{array}$ & $\begin{array}{c}E_{c}=2617789.2 \\
\text { ton } / \mathrm{m}^{2}\end{array}$ & $\begin{array}{c}\text { Modulus of } \\
\text { elasticity }\end{array}$ & $\begin{array}{c}E_{g}=30 \mathrm{Mpa}= \\
3060 \mathrm{ton} / \mathrm{m}^{2}\end{array}$ \\
\hline Poisson's ratio & $\vartheta=0.2$ & Poisson's ratio & $\vartheta_{g}=0.35$ \\
\hline $\begin{array}{c}\text { The wall } \\
\text { thickness }\end{array}$ & $t=0.2 \mathrm{~m}$ & $\begin{array}{c}\text { Thermal coefficient } \\
\text { of expansion }\end{array}$ & $\alpha_{w}=1.2 * 10^{-5}$ \\
\hline
\end{tabular}

Table II shows the comparison between thermal straining actions resulted from FEM and the calculated moment according to ACI at $\Delta T= \pm 30^{\circ} \mathrm{C}$ for both uniform and nonuniform temperature difference. For this scenario, FEM model outputs can be shown in Figures 1 and 2 respectively.

TABLE II. COMPARISON OF THERMAL STRAINING ACTIONS OF FEM AND CALCULATED MOMENT ACCORDING TO ACI AT $\Delta T= \pm 30^{\circ} \mathrm{C}$

\begin{tabular}{|cc|c|c|c|}
\hline \multirow{2}{*}{$\boldsymbol{\Delta}$} & \multicolumn{2}{c|}{$\boldsymbol{\Delta}=+\mathbf{3 0}^{\mathbf{}} \mathbf{C}$} & \multicolumn{2}{c|}{$\Delta \boldsymbol{T}=\mathbf{3 0} \mathbf{0}^{\mathbf{C}}$} \\
\cline { 2 - 5 } & Uniform & Nonuniform & Uniform & Nonuniform \\
\hline MACI (ton.m) & 3.93 & 3.93 & -3.93 & -3.93 \\
\hline M11 (ton.m) & $0^{*}$ & 0.798 & $0^{*}$ & 0.798 \\
\hline M22 (ton.m) & $0^{* *}$ & 0.849 & $0 * *$ & 0.849 \\
\hline F11 (ton) & $0^{* * *}$ & 0 & 50 & 0 \\
F22 (ton) & $0^{* * * *}$ & 0 & 0 & 0 \\
\hline
\end{tabular}

"For the last $0.5 \mathrm{~m}$ an extra moment appears ascending to reach its maximum value at the base $\mathrm{M} 11=1.65$ ton. $\mathrm{m}$

***For the last $2 \mathrm{~m}$, an extra moment appears ascending to reach its maximum value at the base $\mathrm{M} 22=8.26$ ton.m

${ }^{* * *}$ For the last $2 \mathrm{~m}$, an extra compression force appears ascending to reach its maximum value at the base F11=-191.1ton

${ }^{* * * *}$ For the last $0.5 \mathrm{~m}$, an extra compression force appears ascending to reach its maximum value at the base F22=-13.54ton
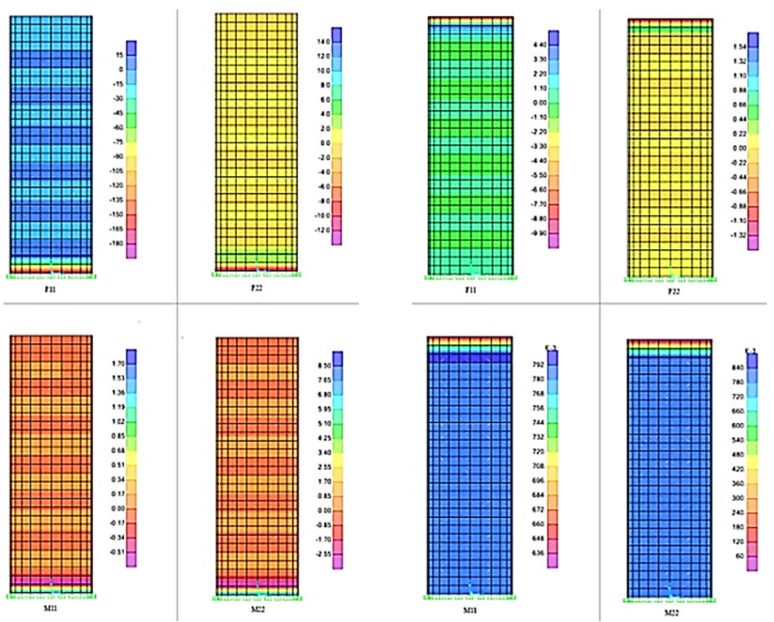

Uniform

Nonuniform

Fig. 1. FEM model outputs for $\Delta T=+30^{\circ} \mathrm{C}$

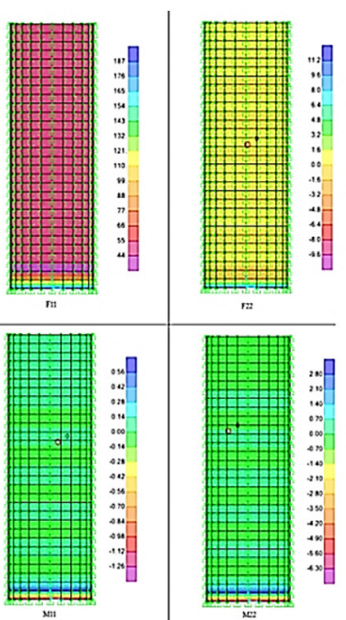

Uniform
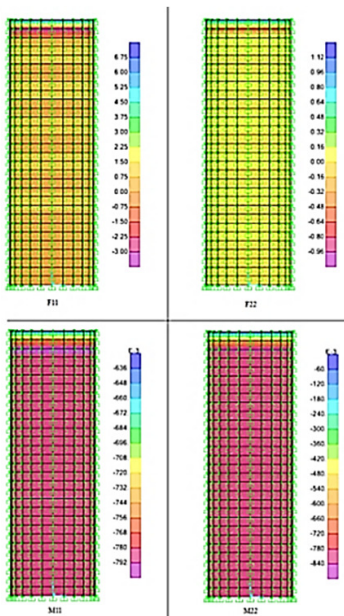

Nonuniform
Fig. 2. FEM model outputs for $\Delta T=-30^{\circ} \mathrm{C}$

Figure 3 shows the comparison between the moment resulting from linear FEM and the additional moment according to ACI. It is clear that the ACI additional moments are larger at all temperature differences which implies that ACI is more conservative than FEM.

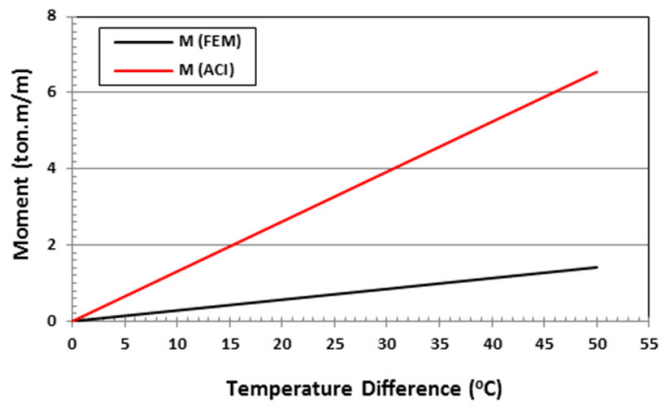

Fig. 3. Comparison between the moments of Linear FEM and ACI for temperature differences $\Delta T$ and silo wall thickness $t=0.2 \mathrm{~m}$ 


\section{B. Silo Wall Thickness}

In (2), the additional moment is directly proportional to the square of the silo wall thickness. Taking the silo data mentioned above, the calculated moment can be written as a function of $\Delta T$ and $t$ as: $M_{t}=3.2722365 t^{2} \Delta T$ (ton $/ \mathrm{m}$ ). Wall thickness $t$ ranges between $0.15 \mathrm{~m}$ and $0.35 \mathrm{~m}$, and $\Delta T$ ranges from $5^{\circ} \mathrm{C}$ to $50^{\circ} \mathrm{C}$. Figures 4 and 5 illustrate the resulted linear FEM moment for the two scenarios of $(t=0.15 \mathrm{~m}$ and $t=0.35 \mathrm{~m})$ for various $\Delta T$.
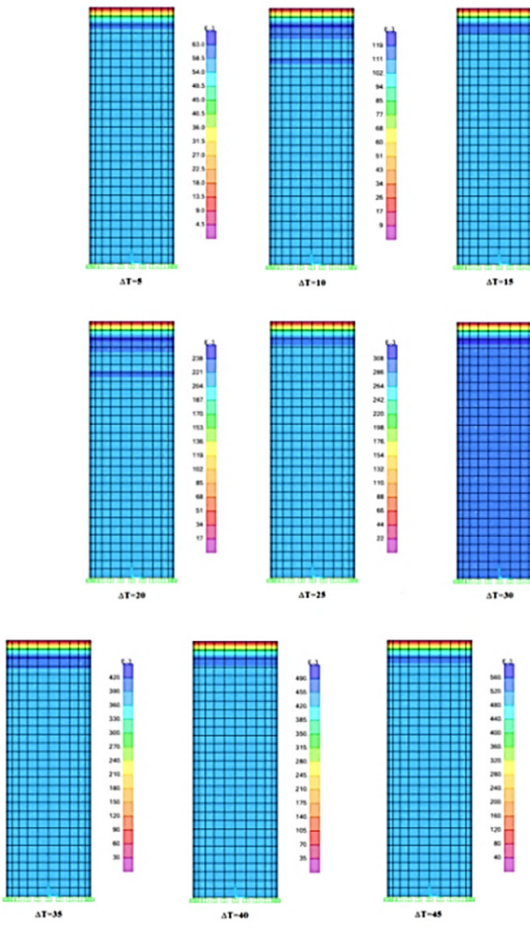

$\rightarrow \rightarrow$
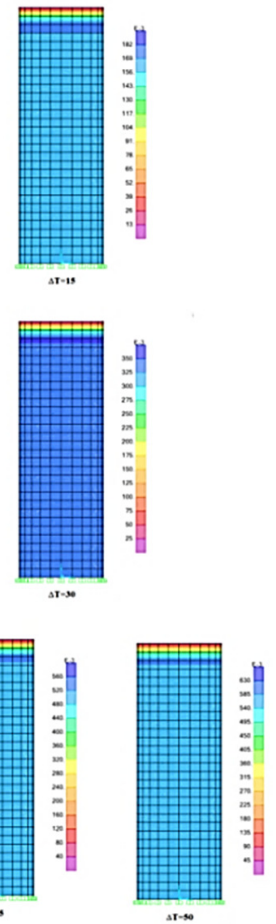

Fig. 4. Linear FEM moment for different $\Delta T$ at $t=0.15 \mathrm{~m}$

Figure 6 illustrates the resulted linear analysis of FEM moments and the calculated ACI moments with different values of $\Delta T$ and $t$ and Figure 7 shows the respective standard deviations. It is clear that the standard deviation varied gradually from 0.4 to 1.8 at $\Delta T=10^{\circ} \mathrm{C}$, which is considered a good matching, to 2.2 to 8.9 at $\Delta T=50^{\circ} \mathrm{C}$, which is a poor matching. On the other hand, nonlinear analysis takes all the applied stress and resulting strains, even if it exceeds yielding strength. Figure 8 illustrates the resulted nonlinear analysis of FEM moments and the calculated ACI moments for different values of $\Delta T$ and $t$ and Figure 9 shows the standard deviations which varied from 0.0 to 1.7 (good matching). From Figures 6 and 8 , it can be noticed that the moments of linear and nonlinear FEM and ACI increase with increasing $\Delta T$ and $t$. In addition, the standard deviation in Figure 7 shows that the moments of linear FEM have a gap lesser than the corresponding values in ACI, especially in higher $\Delta T$ and $t$ values. Furthermore, it can be clearly noticed that the moments of nonlinear FEM are much closer to the ACI results. These results lead to the conclusion that nonlinear analysis is a better matching for ACI results than linear analysis.
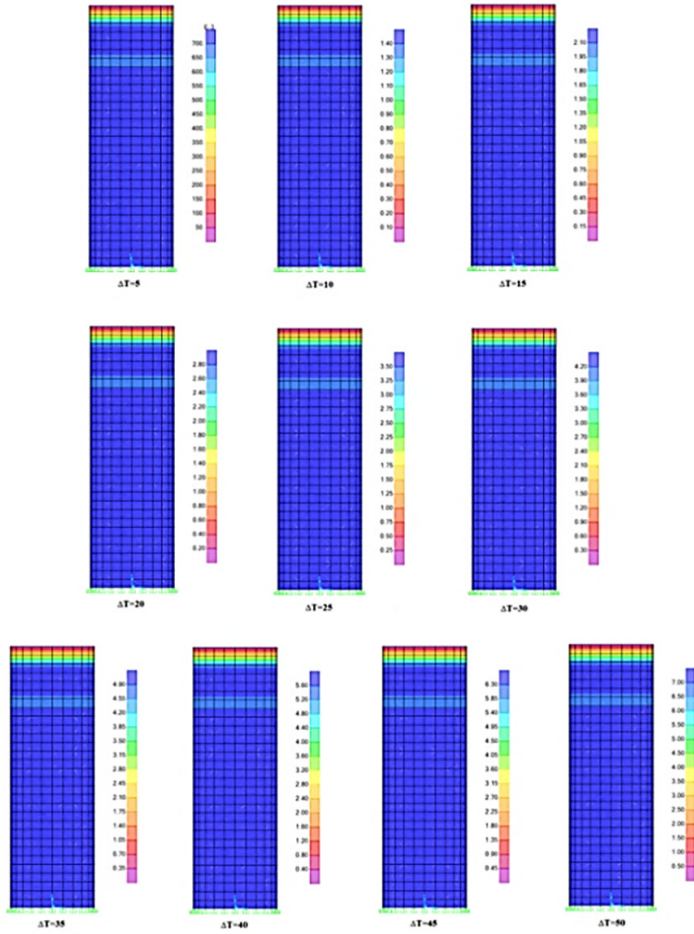

Fig. 5. Linear FEM moment for varying $\Delta T$ at $t=0.35 \mathrm{~m}$

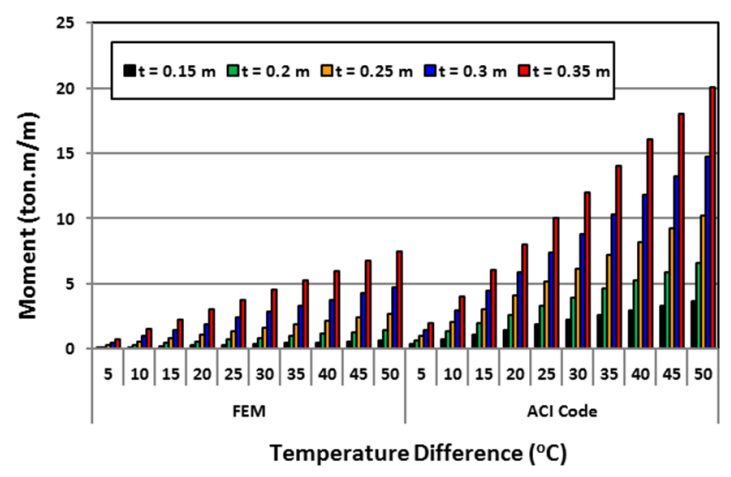

Fig. 6. Linear FEM and ACI moments versus $\Delta T$ and silo wall thickness $t$

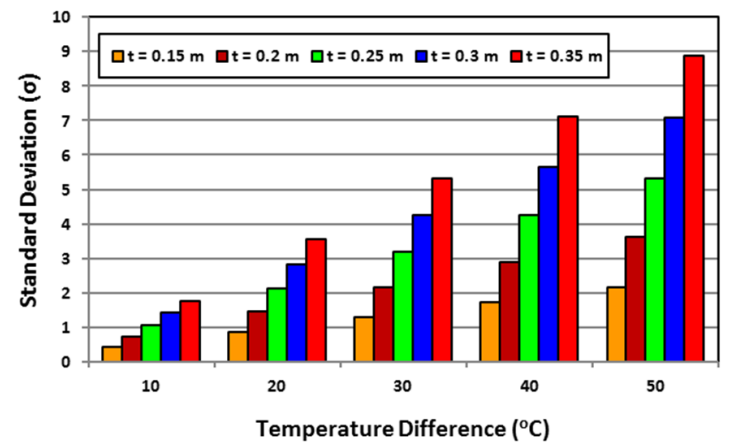

Fig. 7. Standard deviations of Linear FEM and ACI versus $\Delta T$ and $t$ 


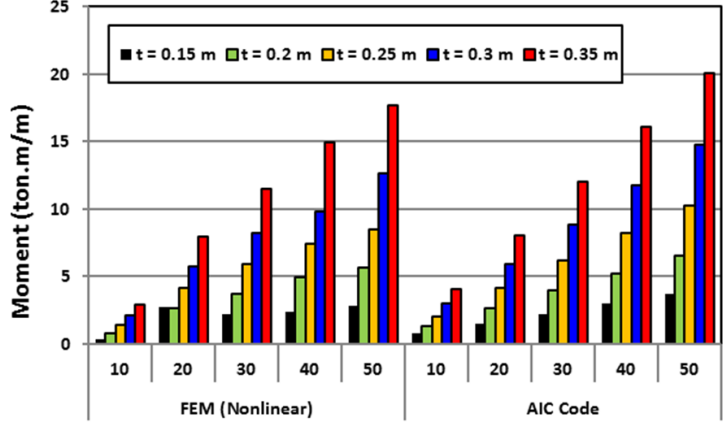

Temperature Difference $\left({ }^{\circ} \mathrm{C}\right)$

Fig. 8. Nonlinear FEM and ACI moments versus $\Delta T$ and $t$

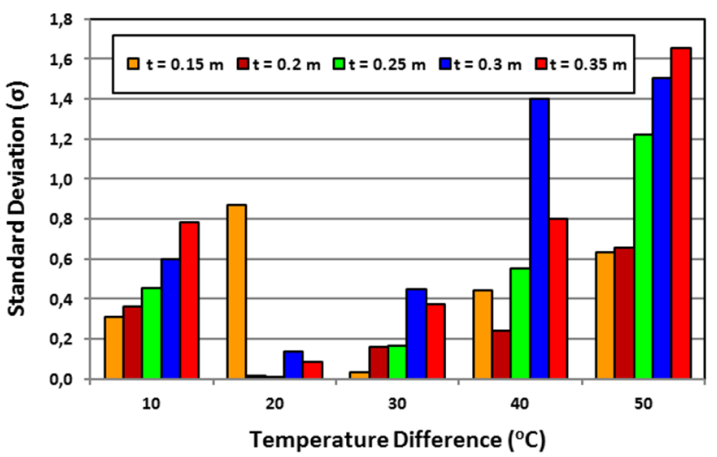

Fig. 9. Standard deviations of nonlinear FEM and ACI versus $\Delta T$ and $t$

\section{SILO HOOP FORCE ANALYSIS UNDER THERMAL LOAD}

To estimate the circumferential force (hoop force) over the silo wall, three estimation systems are presented utilizing FEM, Poland, and EU codes respectively. In Euro code, the calculation of the unloading effective elastic modulus of the stored material $\left(E_{s u}\right)$ mainly depends on the granular material properties (wheat), the depth of which is calculated $(z)$ (the highest depth to be conservative) and the silo inner radius $r$. Table III shows the unloading effective elastic modulus $\left(E_{s u}\right)$ calculations due to changing radius.

TABLE III. UNLOADING EFFECTIVE ELASTIC MODULUS OF THE GRANULAR STORED WHEAT $\left(E_{S E}\right)$

\begin{tabular}{|c|c|c|c|c|}
\hline \multicolumn{2}{|c|}{$r(\mathrm{~m})$} & 2.5 & 5 & 7.5 \\
\hline \multicolumn{2}{|c|}{$z_{o}(\mathrm{~m})$} & 6.09 & 12.18 & 18.27 \\
\hline \multicolumn{2}{|c|}{$z(\mathrm{~m})$} & 28.88 & 27.75 & 26.63 \\
\hline \multirow{4}{*}{ First method } & $P_{h o}\left(\operatorname{ton} / \mathbf{m}^{2}\right)^{*}$ & 2.959 & 5.919 & 8.879 \\
\hline & $Y_{J}$ & 0.99 & 0.89 & 0.77 \\
\hline & $P_{v f t}\left(\operatorname{ton} / \mathbf{m}^{2}\right)^{*}$ & 5.424 & 9.755 & 12.66 \\
\hline & $E_{s u}\left(\operatorname{ton} / \mathrm{m}^{2}\right)^{*}$ & 1025 & 1844 & 2393 \\
\hline \multirow{5}{*}{ Second method } & $h_{o}(\mathrm{~m})$ & 0.562 & 1.124 & 1.686 \\
\hline & $n$ & -1.52 & -1.52 & -1.52 \\
\hline & $z_{v}(\mathbf{m})$ & 7.05 & 11.2 & 13.8 \\
\hline & $P_{v f t}\left(\operatorname{ton} / \mathrm{m}^{2}\right)^{*}$ & 6.35 & 10.08 & 12.42 \\
\hline & $E_{s u}\left(\operatorname{ton} / \mathbf{m}^{2}\right)^{*}$ & 1200 & 2041 & 2347 \\
\hline \multicolumn{2}{|c|}{$E_{s u} \max \left(\operatorname{ton} / \mathbf{m}^{2}\right) *$} & 1200 & 2041 & 2393 \\
\hline
\end{tabular}

Figures 10-12 show the scenario values of the hoop force, resulted from thermal stresses of FEM, versus various values
$\Delta T$, silo wall thickness $t=0.2 \mathrm{~m}$, and silo inner radius $r=2.5 \mathrm{~m}$, $5.0 \mathrm{~m}$, and $7.5 \mathrm{~m}$, respectively.
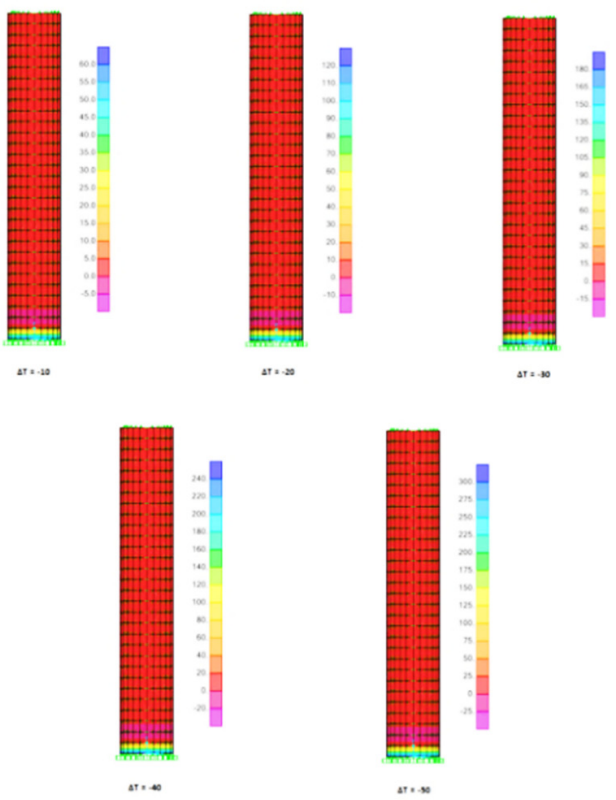

Fig. 10. FEM hoop force for variable $\Delta T$ at $t=0.2 \mathrm{~m}$ and inner radius $r=2.5 \mathrm{~m}$
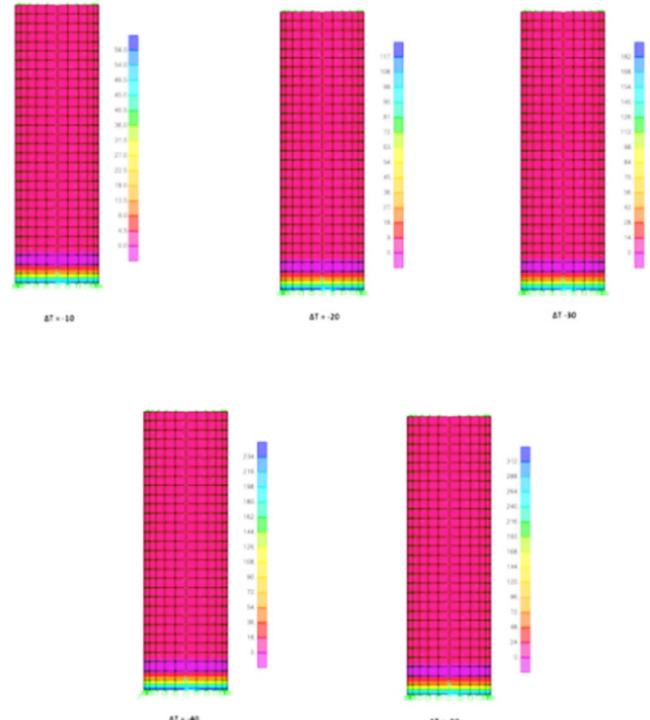

Fig. 11. FEM hoop force for variable $\Delta T$ at $t=0.2 \mathrm{~m}$ and $r=5.0 \mathrm{~m}$

In Figures 13 to 15 , it can be seen that the hoop force increases with increasing $\Delta T$ and $r$ for FEM, Poland, and EU code but insignificantly with the rise in silo wall thickness. The force difference at variant wall thicknesses does not exceed one ton. Figure 16 outlines the effect of temperature difference on the hoop force results. 

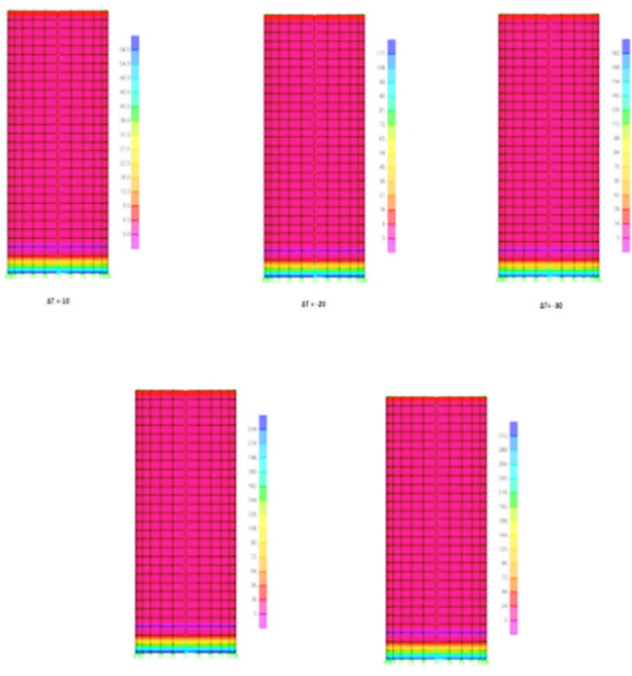

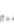

n.m

Fig. 12. FEM hoop force for variable $\Delta T$ at $t=0.2 \mathrm{~m}$ and $r=7.5 \mathrm{~m}$

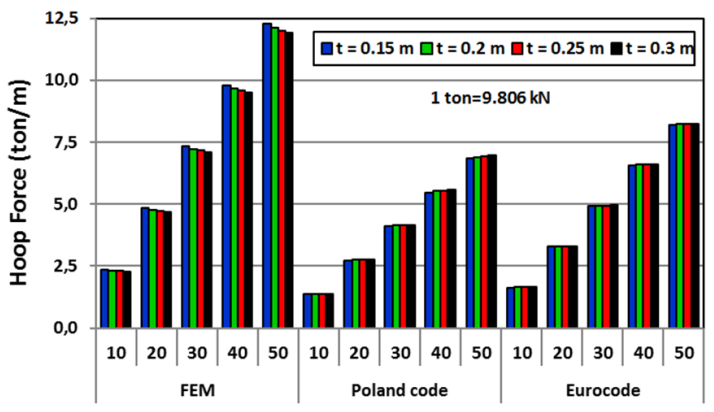

Temperature Difference $\left({ }^{\circ} \mathrm{C}\right)$

Fig. 13. FEM-Poland-Eurocode hoop forces versus $\Delta T$ at $r=2.5 \mathrm{~m}$

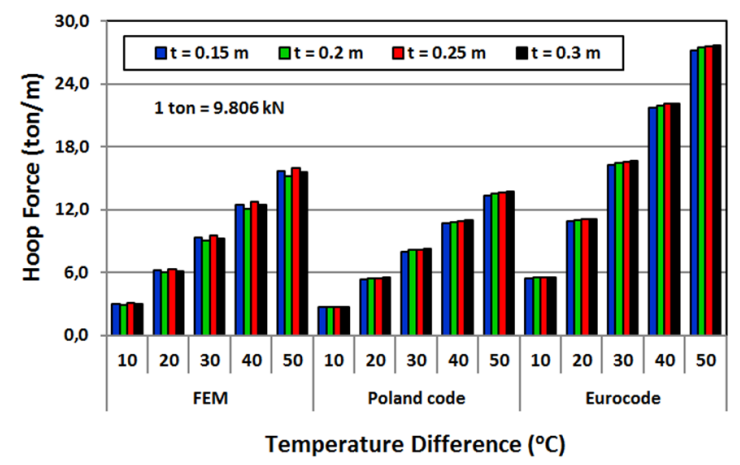

Fig. 14. FEM-Poland-Eurocode hoop forces versus $\Delta T$ at $r=5.0 \mathrm{~m}$

To evaluate FEM performance, Figures 17-18 show the standard deviations for FEM, Polish, and EU code. The standard deviation for FEM and Polish code varied gradually from 0.2 to 1.3 at $r=5.0$ and $7.5 \mathrm{~m}$ (good matching) while it varied from 0.6 to 3.5 at $r=2.5 \mathrm{~m}$ (disgradually matching). The standard deviation for FEM and Eurocode has a variety from 0.5 to 2.6 at $r=2.5 \mathrm{~m}$ (nearly good matching) and from 1.8 to 8.6 at $r=5.0 \mathrm{~m}$ (poor matching) while it has a very highly variety from 3.8 to 18.5 at $r=7.5 \mathrm{~m}$ (very poor matching). So, the results show a nearly good matching between FEM and Poland code, especially in higher values of $r$ and poor matching between FEM and Eurocode.

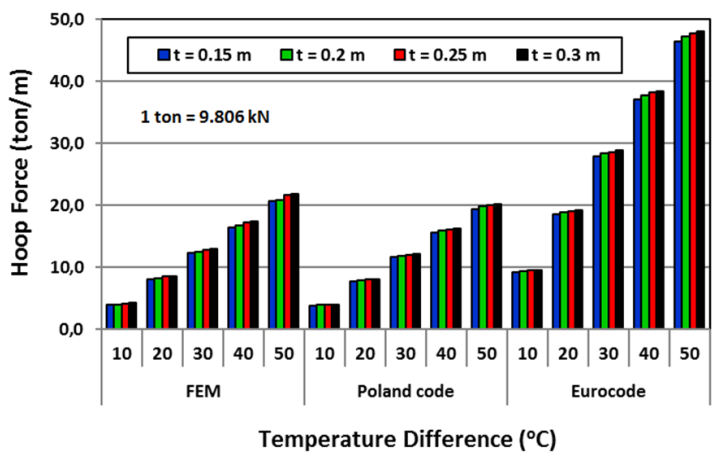

Fig. 15. FEM-Poland-Eurocode hoop forces versus $\Delta T$ at $r=7.5 \mathrm{~m}$

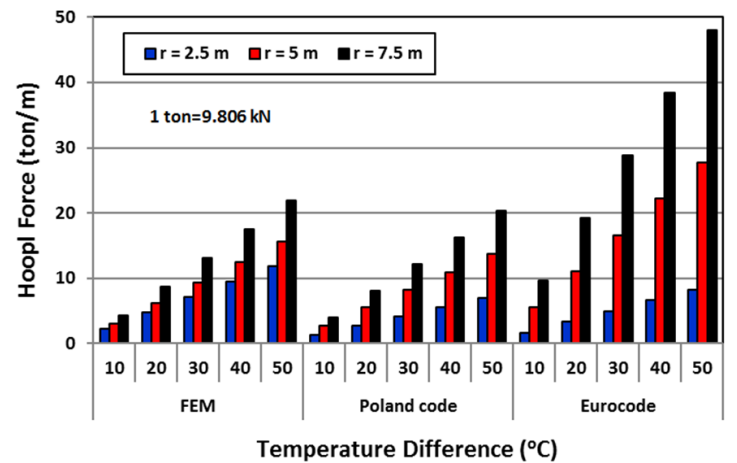

Fig. 16. FEM-Poland-Eurocode hoop forces versus $\Delta T$ and $r$ for $t=0.30 \mathrm{~m}$

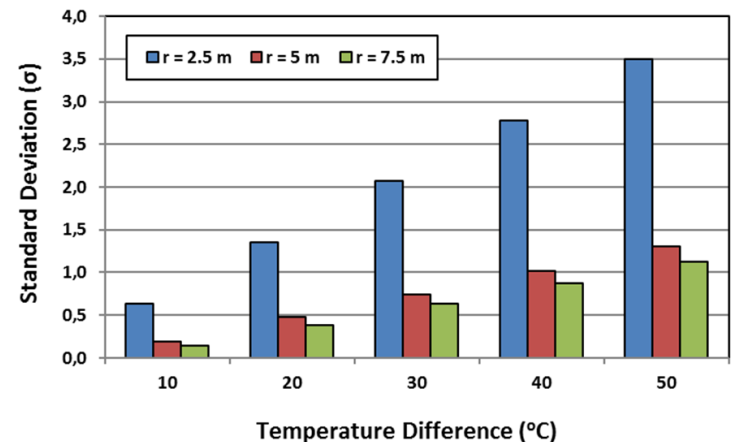

Fig. 17. Standard deviations of FEM and Poland code versus $\Delta T$ and $r$

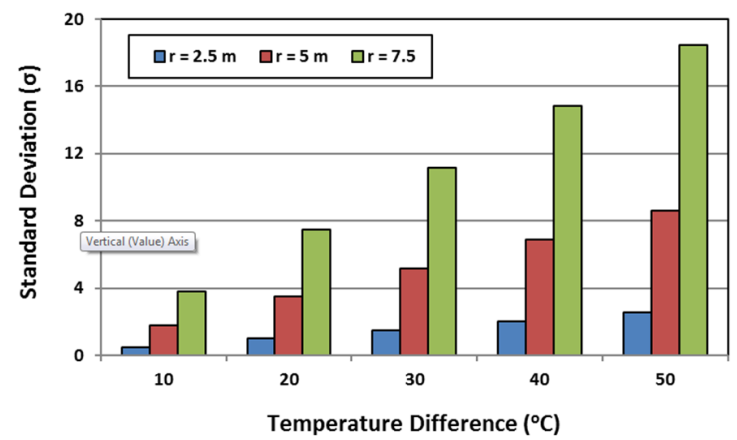

Fig. 18. Standard deviations of FEM and Eurocode versus $\Delta T$ and $r$ 


\section{CONCLUSIONS}

This study has been conducted to evaluate reinforced concrete silos subjected to thermal load by applying a computation analytical FEM using a commercial analyzing program (SAP 2000 v. 16). Various code provisions (ACI, EU, and Poland) were used and compared with the FEM results. These codes were used to estimate the additional moments and hoop forces of silo walls under different thermal loads. The study showed that the thermal actions affected the design through two stresses, tangential oriented stress (circumferential stress) due to thermally induced surcharge pressure during cooling of a filled silo structure, and the stress due to temperature differences at walls. The thermal stresses are affected by many factors like silo wall thickness, silo diameter, silo height, temperature difference, granular material, and concrete properties as the modulus of elasticity, the thermal coefficient of expansion and Poisson's ratio. The thermal stresses are directly proportional to temperature difference, silo wall thickness, silo diameter and silo height. The ACI equation is a rather conservative one, as the thermal stresses obtained using FEM (linear analysis) were lower than the ones given by the ACI code. The moment of nonlinear FEM analysis had a good matching with the corresponding values of ACI leading to the conclusion that nonlinear analysis is more accurate than linear analysis. Moreover, the results regarding hoop forces showed a distinct pattern with the temperature difference, silo wall radius, and insignificant influence of silo wall thickness for FEM, Euro and Poland codes. Further, the hoop force results produced by FEM had a good matching with the corresponding values of Poland code especially for big silo wall radii and poor matching with EU code. This study can be used for rapid determination of critical areas of concern for critical loading combinations and for varying silo configurations. The presented results are extensive and cover many disciplines, but still more work remains to be done. Thermal load combinations and combination factors should be set by dividing silos into different categories, at least according to the relative thickness of the silo walls, different heights and shapes, the aspect ratio of the silo, whether the silo is onground or elevated, and operating conditions.

\section{ACKNOWLEDGMENT}

This research was funded by the Deanship of Scientific Research of the University of Hail, Saudi Arabia, under the contract E-3-CE.

\section{REFERENCES}

[1] A. Vardai, B. Madaras, Dust Explosion of RC Silos, Springer, 2017

[2] S. S. Safarian, E. C. Harris, "Determination of minimum wall thickness and temperature steel in conventionally reinforced circular concrete silos", ACI Journal Proceedings, Vol. 67, No. 7, pp. 539-547, 1970

[3] ACI Committee 313-97, Standard Practice for Design and Construction of Concrete Silos and Stalking Tubes for Storing Materials, ACI, 1997

[4] ASABE Standard EP (R2006), Loads Exerted by Free Flowing Grain on Bins, pp. 773-776, ASABE, 1988

[5] M. Fintel, Handbook of Concrete Engineering, Springer, 1985

[6] ACI Committee 318-14, Building Code Requirements for Structural Concrete and Commentary, ACI, 2014
[7] ACI Committee 313R-97, Commentary on Standard Practice for Design and Construction of Concrete Silos and Stacking Tubes for Storing Granular Materials, ACI, 1997

[8] A. Lapko, J. Prusiel, Stress Analysis of Silo Wall Subjected to Grain Pressure and Thermal Actions, University of Bialystok, 1997

[9] S. Das, M. N. S. Hadi, Non-Linear Finite Element Analysis of Reinforced Concrete Members Using MSC/NASTRAN, University of Wollongong, 1996

[10] American Society of Heating, Refrigerating and Air Conditioning Engineers, Ashrae Guide and Data Book, American Society of Heating, Refrigerating and Air Conditioning Engineers, 1964

[11] European Standards, EN 1991-4 (2006): Eurocode 1-Actions on Structure -Part 4: Silos and Tanks, European Standards, 2006

[12] DIN 1055-6:2005, Actions on structures - Part 6: Design loads for buildings and loads in silo bins, DIN, 2005 (in German)

[13] PN-B-03262, Reinforced concrete tanks for bulk materials and silage, Static calculations and designing, the whole standard, PKN, 2002 (in Polish)

[14] The origins of the Finite Element Method, available at: http://home.iitk.ac.in/ mohite/History_of_FEM.pdf, [accessed: April 15, 2015]

[15] D. L. Logan, A First Course in the Finite Element Method, University of Wisconsin, 2012

[16] K. Guo, C. Zhou, X. Zhang, L. Meng, "Lateral pressure of RC silos with static and dynamic granular materials", Journal of Harbin Institute of Technology (New Series), Vol. 22, No. 4, pp. 92-98, 2015

[17] B. Vicich, C. Ryan, K. Meredith, Linear vs. Non-Linear Contact Analysis, Samtec Incorporation, 2007

[18] http://hyperphysics.phy-astr.gsu.edu/hbase/permot2.html

[19] ECP Committee 203-2007, Egyptian Code for Design and Construction of Concrete Structures, ECP, 2007

[20] Bureau of Indian Standards, IS-456 (2000): Plain and Reinforced Concrete Code of Practice, Bureau of Indian Standards, 2000

[21] http://www.slideshare.net/ved_ram/linear-non-linear-30849335

[22] V. Ivanco, Nonlinear Finite Element Analysis, Technical University of Kosice, 2011

[23] L. Zhao, Z. Yang, L. Wang, "Investigation on the Non-Uniform Temperature Distribution of Large-Diameter Concrete Silos Under Solar Radiation", Mathematical Problems in Engineering, Vol. 2018, Article ID 5304974, 2018

[24] E. J. Hearn, Mechanics of Materials, University of Warwick, 1997

\section{AUTHORS PROFILE}

Walid M. A. Khalifa received his BSc in Civil Engineering from Cairo University, Egypt in 1988 and his $\mathrm{PhD}$ in Water Resources and Environmental Hydrology from Cairo University in 2000. He is currently an assistant professor in Hail University, Saudi Arabia, and Fayoum University, Egypt. His research interests include predictive water quality and hydrodynamics in surface water bodies and in reinforced concrete water structures.

Khaled F. O. El-Kashif received his BSc in Civil Engineering from Cairo University, Egypt in 1997, and his $\mathrm{PhD}$ in Structural Engineering from Tokyo University, Japan in 2003. He is currently an assistant professor in Cairo University, Egypt. His research interests include Structural Engineering for concrete and steel. 